\title{
Del viajero al turista hiperconectado
}

\section{From the Traveler to the Hyperconnected Tourist}

\author{
ALMUDENA MANIBARDO BELTRÁN (Universidad de Castilla-La Mancha), ANTONIO \\ FERNÁNDEZ VICENTE (Universidad de Castilla-La Mancha) y GAIA PERUZZI (Sapienza- \\ Università di Roma).
}

Artículo recibido: 14 de marzo de 2020

Solicitud de revisión: 14 de mayo de 2020

Artículo aceptado: 26 de junio de 2020

Manibardo Beltrán, Almudena, Fernández Vicente, Antonio y Peruzzi, Gaia (2021). Del viajero al turista hiperconectado. Recerca. Revista de Pensament i Análisi, 26(1), pp. 111132. doi: http://dx.doi.org/10.6035/Recerca.2021.26.1.6

\section{Resumen}

El artículo trata de aclarar la contraposición de la figura del turista contemporáneo frente a la del viajero romántico. A partir de un cuadro conceptual teórico, se trata de forjar un aparato crítico para problematizar la influencia de las tecnologías de la hiperconexión en el viaje actual como una de las industrias culturales. Será, pues, conforme a categorías tales como lo imprevisto, el viaje como transformación y la autenticidad como el texto se aproxime a una crítica del turista hiperconectado, en especial a través del smartphone, a partir de los ideales de viajero que se remontan al Grand Tour.

Palabras clave: turismo, viajes, sociología de la cultura, sociología del ocio, filosofía de la tecnología, smartphone, teoría crítica.

\section{Abstract}

This article tries to clarify the contrast between the contemporary tourist figure and the romantic traveler. From a conceptual and theoretical framework, it is our aim to establish a critical apparatus to problematize the influence of new media in the experience of travel nowadays, as a part of the Industry of Culture. From categories of analysis such as the unexpected, the travel as a personal transformation or the authenticity, our essay deals with a critical perspective of the hyperconnected tourist, specially through the smartphone, from the point of view of the ideals of the romantic traveler and the Grand Tour.

Key Words: tourism, travels, sociology of culture, sociology of leisure, philosophy of technology, critical theory. 


\section{INTRODUCCIÓN}

El ideal de viajero se contrapone hoy a la imagen del turista. El aura romántica del viaje se ha visto eclipsada por la industrialización de los desplazamientos. Así, la palabra turista puede suscitar una acepción peyorativa. Se le atribuye un rol pasivo como espectador de un espectáculo escenificado. Ocurre como en las observaciones de Adorno y Horkheimer acerca de las industrias culturales. Las diversiones que sirven para atenuar los rigores del trabajo mecanizado han de proporcionar gratificaciones estériles: «El placer se petrifica en aburrimiento, pues para seguir siendo tal no debe costar esfuerzos y debe por tanto moverse estrictamente en los raíles de las asociaciones habituales» (Adorno y Horkheimer, 2004: 181).

Sin embargo, en el imaginario colectivo, la industria del turismo se hace eco del ideal romántico para integrarlo como parte del consumo de experiencias de viaje. Y, al mismo tiempo, la concepción del turista se ve afectada por la sospecha de la inautenticidad y la banalización de los viajes.

Por otra parte, la figura del turista y el viaje, que se ha visto transformada con cada innovación en los medios de transporte, también muta con la emergencia de los dispositivos digitales de comunicación. En concreto, se hace necesario establecer una serie de patrones conceptuales para abordar los desafíos que, en nuestro caso, el smartphone, como tecnología disruptiva que hiperconecta al viajero, plantea en las prácticas turísticas.

El artículo trata así de forjar un aparato crítico que muestre los ejes de contraste entre el viajero en su acepción ideal y el turista en sus distintas vertientes prácticas. Buscamos, por tanto, identificar cuáles son los rasgos principales del viaje que fundamentan una teoría crítica del turismo en la época contemporánea, afectada en gran medida por la tecnología digital.

Entendemos el turismo como una de las instituciones culturales, que Axel Honneth define como «factores de estabilización» que incorporan «expectativas de comportamientos» (Honneth, 2009: 62). Se relaciona con los modos de ser que cristalizan como normativos, en este caso, en lo que a la forma de viajar se refiere.

El artículo responde a una metodología puramente ensayística y teórica. Permita el lector que el texto incluya referencias literarias, algunas de gran belleza, para ilustrar en especial los rasgos definitorios del viaje. De este modo, forma y contenido se entrelazan para favorecer la mejor comprensión de los conceptos propuestos. Además de estudios clásicos sobre la figura del turista, como los de Dean McCannell y John Urry, nuestro ensayo contextualizará 
tales teorías con la sociología crítica que enmarque el turismo como una de las industrias culturales.

\section{EL IDEAL DE VIAJERO}

¿Cómo podríamos describir ese ideal de viajero? Sin duda, la imagen romántica del viajero se remonta a toda la corriente de literatura de viajes, desde la Historia de Heródoto y La Odisea homérica (Encinas Reguero, 2018) hasta los viajeros románticos en busca de lo exótico en Oriente (Soriano, 2009).

\subsection{El viajero y la transformación}

En la etimología de la palabra viaje, nos señala Paul Zumthor, la voz inglesa travel proviene del francés travail. La voz alemana Reise procede a su vez del germánico rîsan, que remite también al esfuerzo. El viajero se niega a permanecer en la morada y guarda el deseo de cambio como aspiración a la sabiduría. En castellano, viaje proviene de viaticum, que indica 'camino, transición de un punto a otro'.

El 'viaje' pone en marcha nuestra capacidad para cruzar un límite, para afrontar una alteridad. La idea (tanto como el hecho mismo) del viaje manifiesta nuestra tendencia innata al desplazamiento, da una perspectiva a esta movilidad que es la primera conquista espacial del niño: perspectiva que es la de un deseo de conocimiento (Zumthor, 1994: 163).

De hecho, ya en 1977, Marc Augé señalaba cómo la idea de viaje en tanto encuentro con la diferencia se vuelve cada vez más infrecuente. En su crítica al turismo como consumo de masas se deja entrever una nostalgia por esos encuentros cognitivos con otras culturas, que ha sido el leitmotiv de los desplazamientos antropológicos, frente al esquematismo del turismo y las agencias de viaje (Augé, 1998: 15-16).

Podríamos vincular esa aura romántica del viaje como rito de paso, con el advenimiento del Grand Tour (la voz turismo proviene del francés tour) entre la aristocracia europea en los siglos XVIII y XIX. Ese viaje de los jóvenes del norte de Europa hacia el sur se caracterizaba por adoptar el carácter de desplazamiento iniciático, «de regeneración, en el que se dejaba atrás la personalidad anterior y se volvía diferente de como se había ido» (Belmonte, 2015: 8).

En primer lugar, el viajero ha de atesorar una disposición abierta a ese desplazamiento no solo espacial, sino mental. El viaje es el escenario para el 
ejercicio de la curiositas y para el abandono de los paisajes acostumbrados: «El curioso vive de la diferencia, de lo otro; para explicar el mito de Narciso nunca traeríamos a colación la curiositas, pues para esta es esencial superar la fase del espejo e ir más allá» (Ossola, 2012: 265).

Es lo que la antropología cultural ha llamado alteridad, en tanto encuentro con lo otro: «Uno se abre a la alteridad y puede conocer cómo ven el mundo las otras culturas y sociedades y cómo se enfrentan a él» (Wulf, 20o8: 113). Se trata del contrapeso que se opone a las estrategias europeas señaladas por Cristoph Wulf como herramientas para limitar el encuentro con la diversidad, tales como el logocentrismo, el egocentrismo y el etnocentrismo.

Además, el viajero ha de ser permeable a la adaptación. Laurence Sterne en su Viaje sentimental satirizaba la disposición rígida en los viajes. En especial, su obra representaba en cierto modo la parodia de Travels through France and Italy de Tobis Smollett, quien tiene como personaje correlativo a Smelfungus.

El sabio Smelfungus viajó de Bolonia a París, de París a Roma, y así prosiguió. Pero emprendió el viaje afectado de melancolía e ictericia y todo cuanto vio quedó descolorido o distorsionado en su memoria. Escribió una descripción de ese recorrido, aunque no es otra cosa que la descripción de sus míseros sentimientos (Sterne, 2017: 84).

Un viaje sentimental es el que desencadena emociones que operan una transformación esencial en el viajero permeable al cambio. La disposición rígida del sabio Smelfungus ante lo extraño es, pues, contraria a la exploración de la alteridad. Lo escrito por Sterne da cuenta de esta fascinación por la novedad y lo que es diferente a uno mismo, como advirtió Virginia Woolf:

Quien escribe, lo que sea, cuando viaja al extranjero escribe un diario de impresiones. El escenario es tan nuevo, tan original y está dispuesto con tanto encanto a fin de que lo miren y escriban al respecto, que los dedos se curvan en torno a un lápiz visionario y los labios forman palabras instintivamente (Woolf, 2001: 89).

\subsection{Lo inesperado y el descubrimiento}

El viaje es una especie de lectura práctica del territorio y las geografías, semejante a la comprensión de la vida como un viaje. En ese viaje, los encuentros fortuitos y lo imprevisto han de teñir los recorridos e itinerarios y obligarnos a formular preguntas (Manguel, 2015: 53).

Ese continuo preguntarse por lo que nos rodea y no es uno mismo no es solo patrimonio del desplazamiento geográfico. Del mismo modo, la curiosi- 
dad puede dirigirse hacia lo más próximo, de forma que se desfamiliarice el entorno habitual. Es una aplicación espacial a lo que el teórico Viktor Shklovski (2012) llamaba extrañamiento, en contra de la algebrización. Para reconocer la singularidad de los objetos, los paisajes y los individuos, urge concentrar la atención hasta que parezca que es la primera vez que se los ve.

Es en este sentido que el viaje debería maravillar al viajero, encandilado en cierto modo por esos paisajes desacostumbrados. Tal y como los relatos de viaje de Marco Polo fueron consignados como El libro de las maravillas. Pero es una condición sine qua non para que el viaje adopte ese sentido de descubrimiento (Boorstin, 2000) y ampliación de los horizontes cognitivos: el hecho de enfrentarse a lo inesperado. Robert Louis Stevenson, que fue un experimentado viajero, expresaba así esta disposición:

De modo que en cualquier parte a la que un hombre vaya podrá encontrar algo que le complazca y le llene de calma: en la ciudad, los rostros agradables de mujeres y hombres, las bellas flores que adornan las ventanas; podrá oír cantar a un pájaro enjaulado en la esquina del callejón más sombrío; y en el campo... no hay rincón del campo que no encierre algo entretenido. Dejemos que el viajero lo busque con el estado de ánimo adecuado (Stevenson, 2014: 31).

El situacionismo trató de recuperar ese sentido de búsqueda de lo imprevisible e inesperado, por ejemplo en Vaneigem y Guy Debord: «Cada reposo es una dimisión» (Perniola, 2008: 107). Es en cierto modo lo que se expresaba en las prácticas denominadas desvío y deriva (Debord, 2006: 221 y ss.; 251 y ss.): se trataba de propiciar la emergencia de nuevas situaciones lúdico-constructivas que rompiesen con los esquemas prácticos acostumbrados, por ejemplo en la vivencia de la ciudad. También desde el grupo de vanguardia denominado Stalker (La Cecla, 2011: 141 y ss.) se ha reivindicado este deambular sin propósito y sin rumbo, esta vez no solo en el ámbito urbano. Es el arte de perderse, de «merodear sin objeto como un simple vagabundo», como solía hacer Dickens (2010: 88), que contrasta sin duda con ese itinerario prefijado que será la base de la industrialización del viaje en el turismo masivo.

\subsection{Remedio contra el tedio}

Es una de las maneras de evitar la rutina, ahuyentar la melancolía y romper con lo familiar. Especialmente en épocas en las que la vida cotidiana tiende a volverse rutinaria y carente de misterio, en un mundo weberiano desencan- 
tado. Herman Melville comenzaba su monumental Moby Dick de esta forma al hacerse a la mar, que es metáfora de la incertidumbre:

Cada vez que me sorprendo con una expresión de tristeza en la boca que va en aumento; cada vez que un húmedo noviembre de lloviznas anida en mi alma; cada vez que me descubro deteniéndome involuntariamente ante las tiendas de ataúdes, y siguiendo a cualquier funeral con que me encuentro; y especialmente si la hipocondría me domina de tal modo que hace falta un sólido principio moral para no salir a la calle y derribar metódicamente los sombreros de los transeúntes, entonces, comprendo que ha llegado la hora de hacerme a la mar cuanto antes. Éste es mi sustituto para la pistola y la bala (Melville, 2009: 31).

El viajero es aquel que quiere trascender su visión del mundo. En cierto modo, lo que desea es salir de sí mismo e, incluso, huir de sus hábitos y familiaridades. Es una de las formas modernas de desaparecer (Le Breton, 2019).

Como, por ejemplo, la vida errante de los caballeros andantes, caracterizados tanto por la horizontalidad y el caminar, como por la apertura, el descubrimiento y la imprevisibilidad (Zumthor, 1994: 194 y ss.). El nomadismo del viajero requiere que el que se desplaza haga del camino su morada. Ya en la modernidad, los sentimientos de spleen y hastío existencial sugieren movimientos trascendentales hacia la alteridad y el salir de las estrechas paredes de nuestros mundos particulares. Es lo que se refleja en el poema Le voyage: «Nous voulons voyager sans vapeur et sans toile! Faites, pour égayer l'ennui de nos prisons» (Baudelaire, 2007: 379). ${ }^{.}$Así lo leemos en Anywhere out of the world, de Charles Baudelaire:

Esta vida es un hospital en que cada enfermo siente el ansia obsesiva de cambiar de cama. A unos les complacería padecer junto a la caldera; otros, en cambio, creen que sanarían al lado de la ventana. Siempre se me antoja que estaría mejor allá donde no estoy, y esta cuestión de mudanza es una de las que discuto constantemente con mi alma (Baudelaire, 2008: 121).

\section{EL TURISTA COMO VIAJERO DOMESTICADO}

La industrialización de los viajes y su inclusión como experiencia de consumo han transformado este sentido primigenio del viaje de descubrimiento

«iQueremos viajar sin vapor y sin tela! Hacedlo, para animar el tedio de nuestras prisiones» (traducción de los autores). 
iniciático y deseo de cambio. A partir de la segunda mitad del siglo XIX, los viajes se multiplican y se democratizan. Una vez entra en la esfera del consumo, la imprevisibilidad y la incertidumbre han de conjugarse con la necesidad de confort y seguridad de los viajeros convertidos en clientes de paquetes y visitas turísticas.

\subsection{Del turista al posturista}

La voluntad de sortir de sa coquille, por utilizar términos de Gaston Bachelard (1993), viene propiciada por la sensación de enclaustramiento en un mundo desencantado, falto de misterio y aventuras. A la sensación de habitar una jaula de hierro weberiana (Weber, 1993) sucede una reacción por la carencia de esa dimensión de libertad y azar sentida por el Entzauberung der Welt.

En 1926, el escritor Stefan Zweig, para quien «los puertos y las estaciones son mi verdadera pasión» (2016: 89), hacía notar este descontento frente a las comodidades del viaje convertido en turismo. En lugar de viajeros, Zweig denomina a los turistas viajados. Se pasa del azar veleidoso (el Dios del viajero, para Zweig), el esfuerzo y lo incierto a los viajes programados y a la organización matemática. Y tampoco se abandona lo propio, según Zweig: el disfrute del viaje no solamente estriba en la lejanía, sino en «no-estar-en-casa y, por ello también, del no-ser-uno-mismo» (Zweig, 2016: 91).

En un mundo en cierto modo sometido a rígidas rutinas, se hace más urgente la salida voluntaria de esas prácticas sistematizadas y, en cierto modo, Mcdonalizadas (Ritzer, 2002). Es lo que ya advertía Zweig a propósito de su asombro al observar los autores de viajes organizados en París:

Que nuestra vida diaria sea cada vez más mecánica, que circule por los pulidos raíles de un siglo tecnificado es algo que no podemos evitar, y tampoco queremos hacerlo, ya que así nos ahorramos muchos esfuerzos. Pero el viaje debe seguir siendo derroche, sumisión del orden al azar y de lo cotidiano a lo excepcional, debe seguir siendo la expresión más personal y auténtica de nuestras inclinaciones; de ahí que tengamos que protegerlo frente a la nueva, burocrática y mecánica forma de turismo masivo e industrializado (Zweig, 2016: 93-94).

La racionalización propia de la modernidad también alcanza al turismo. En este sentido, la predicción y la estandarización global domestican el componente de aleas del viaje romántico. A propósito, la generalización como modelo de los Holyday Inn (Ritzer, 2002: 109). 
Pero, al mismo tiempo que el turismo propicia una evasión que reencanta un mundo desencantado (Ritzer, 2000), la pregunta es hasta qué punto se preservan los paradigmas de la eficiencia y el control en los viajes turísticos. Ritzer observaba que, además de experiencias, el turismo se orienta al consumo de productos, en tanto los centros comerciales se han convertido en destinos turísticos. Incluso los cruceros se pueden entender como un remedo en movimiento de los grandes centros comerciales, que denomina «catedrales del consumo» (Ritzer, 2000: 150).

Pero el turismo como experiencia propia de la modernidad no puede ser ajeno a la novedad. La búsqueda del asombro es uno de sus reclamos como producto masivo. Ese impulso a la transformación y al conocimiento también es patrimonio del deseo de ser moderno del turista (Wang, 200o). La práctica social del turismo se define por contraste con la rutina y los tiempos laborales del trabajo regulado y organizado. El movimiento en el espacio que es el viaje traslada al turista por un breve periodo fuera de los lugares normales, con la voluntad de retorno (Urry, 1990).

Pero, antes que viajes de carácter individual, caen en la esfera de lo masivo, en tanto los lugares elegidos se someten a un proceso de anticipación. Los itinerarios prescritos formalizan y estandarizan el aleas de los viajes. Los imaginarios del turismo, que se nutren tanto de films, como de la literatura, la televisión, las revistas y, hoy en día, los medios en línea, son las fuentes de atracción que intermedian los destinos turísticos deseables.

Al mismo tiempo se transforma la mirada del viajero. La mirada del turista se constituye a través de la observación y delectación ante un paisaje natural, urbano o humano, que no es el acostumbrado. La atención se dirige a las características que separan ese paisaje o escenas respecto a la experiencia cotidiana. Es lo que se separa de lo habitual, de la repetición de esquemas prácticos de la vida corriente, que en la modernidad se percibe como escenarios de alienación (Lefebvre, 1981).

El turista se dirige hacia lo extraordinario y lo exótico. Siegfried Kracauer advertía que en el viaje moderno lo que se busca no es una meta del alma, como en el viaje de Goethe a Italia: es un cambio de lugar para devenir seres estéticos cuya delectación es la contemplación. «Cuando viajamos somos como niños, nos alegramos ingenuamente de la nueva velocidad, del libre andar, del espectáculo de complejos geográficos que hasta entonces resultaban inimaginables» (Kracauer, 2008: 48). El turismo pone en juego el hecho de que el ser humano, como observaba Georg Simmel (1986), es un ser de diferencias, vive de ellas. La diferencia espacial de dejar el ambiente doméstico. Y también la 
diferencia de dejar a un lado el trabajo y adentrarse en tiempos de ocio, innecesarios e improductivos.

Pero el turista en su dimensión de ruptura de la vida cotidiana no acaba de asumir esa dificultad y esfuerzo que es propio del viajero. A la comodidad física se le une la tranquilidad mental: «Es un consumidor de exotismo [...] pero, aunque se encuentre en otro lugar, siempre seguirá estando en su país» (Augé, 2007: 63-64).

El imprevisto ha de proporcionarse bajo la seguridad de que serán sucesos en cierto modo domesticados. El viaje turístico ha de ser eficaz y, en ese sentido, lo incierto y aleatorio son dimensiones tangenciales a la experiencia del turista (Lecoquierre, 2008: 197).

Para el hastío de la vida corriente, el turismo de excitación provee de estímulos nerviosos. Para quien sufre de una vida estresante, el turismo de relajación ofrece la diferencia de la tranquilidad absoluta, por ejemplo en los paquetes del Club Med. Lo cual es una reacción que proporciona las emociones que atenúan los efectos perniciosos del trabajo alienado. Lo hace atendiendo a una naturalidad despojada de riesgos (Alaluf, 2019: 64). Esas prácticas sociales del turista están también organizadas y sistematizadas. Son una compensación a la insatisfacción de la vida corriente. Es decir, se someten a la racionalización que controla los riesgos y reduce los imprevistos, propios del viaje romántico.

No obstante, el escritor Antonio Tabucchi nos aleja de las comprensiones monocolor del turismo: siempre existe la posibilidad de que en el viaje programado el turista encuentre por sí solo y se desvíe de los itinerarios prefijados (Tabucchi, 2012: 232). Es lo que ha consignado la psiquiatra Graziella Magherini (1996) a propósito de la patología denominada síndrome Stendhal, que afecta a turistas extasiados por la belleza en Florencia.

El llamado turismo de mochila trata de evitar los itinerarios turísticos al uso y recuperar así el aura de aventura y camino propio del viajero romántico. Es lo propio de exploradores y se vende según la antigua acepción de viaje en tanto desafío e incluso arte de perderse: «Viaggiare e la mitologia moderna delle agenzie di viaggio, delle guide ai paesi lontani, del viaggio-avventura possono essere interpretate come un banale e disperato tentativo di fare commercio del perdersi» (La Cecla, 2011. 27). ${ }^{2}$

«Viajar y la mitología moderna de las agencias de viaje, de las guías a países lejanos, del viaje aventura pueden ser interpretadas como un banal y desesperado intento de convertir el perderse en un negocio» (traducción de los autores). 
El turismo en alguna de sus formas constituye en este sentido un ocio alienado (Xue, Manuel Navarrete y Buzinde, 2014), que es reflejo de la estructura social en la que pasó a ser un fenómeno de masas. Los viajes se estandarizan y se configuran de acuerdo con la lógica del beneficio económico y el consumo. Encontramos ejemplos en las guías de viaje y las rutas turísticas, como las organizadas por Thomas Cook en el XIX, que sirvieron para estructurar y simplificar los desplazamientos. Con el fin de conjugar la experiencia de aventura, de descubrimiento y desfamiliarización con la seguridad y el confort, aunque sea mínimo del consumidor, se editaron guías como la Baedeker en 1828. De esta guía de viaje, Virginia Woolf aclaró que

nadie piensa en leerla por placer, porque quizá sea el más impersonal de los libros, e incluso a los turistas les gusta que los traten como a seres humanos. Proporciona datos en abundancia, pero espera que el lector saque sus propias conclusiones (Woolf, 2001: 145).

No obstante, las guías estructuran los itinerarios y enmarcan los lugares de acuerdo con informaciones performativas. Su labor es aquí la de ofrecer itinerarios aconsejados a un grupo social determinado, como en las guías azules, pero sin que tal intermediación obstaculice el carácter genuino y la impresión de libertad del turista. Es lo que MacCannell observa acerca de la búsqueda de autenticidad en el viaje turístico. El propósito de contemplar la vida real marca la voluntad del turista, que está motivado «por el deseo de ver la vida como realmente se vive, incluso mezclarse con los nativos» (MacCannell, 2003: 125).

Pero, una vez las escenas se enmarcan (un marcador es una información sobre la vista) y se conceptualizan como algo digno de verse por parte de los turistas, lo que se producen son pseudoacontecimientos. Se pierde irremisiblemente esa autenticidad al tratarse de atracciones escenificadas. Erik Cohen (2005) nos advierte de que el posturista se ha resignado a la idea de que la autenticidad, aunque sea representada, y la búsqueda de lo extraordinario son una entelequia inalcanzable. No se preocupa por lo genuino y prefiere lo sucedáneo a lo auténtico. Los parques temáticos en lo que se llama turismo de fantasía vendrían a ser el paradigma de esta deriva del turismo en cierto modo disneyficado (Brunel, 2006).

El turismo extremo, cuyo paroxismo es el turismo espacial (Cohen y Spector, 2019), aún busca esa autenticidad de la experiencia, la excitación y la emoción de hallarse ante territorios desconocidos y peligrosos. Es una forma de reencantar el viaje en el marco del turismo. 
En consecuencia, la definición de turismo depende de las condiciones coyunturales que delimitan las experiencias (Urry y Larsen, 2011). Por ejemplo, la tensión entre autenticidad y recreación espectacular se inscribe como eje vertebrador del turismo en una época de creciente alienación y pérdida de sentido, toda vez se ha industrializado como una experiencia mercantilizada al servicio del capitalismo.

Lo que podríamos denominar posturismo plantea ese desdibujamiento e hibridación entre vida cotidiana y viaje, heredero de las consideraciones románticas de convertir la vida entera en una obra de arte. Se difuminan las fronteras entre lo que es o no turismo, porque esa experiencia de extrañamiento quiere vivirse en el seno de la vida cotidiana. Lo cual plantea problemas irresolubles sobre la demarcación de lo que puede definirse como turismo y lo que no. La mirada del turista es también la del explorador de la vida ordinaria. O quiere serlo, impelido por el deseo de reencantar lo cotidiano. En este contexto, lo que MaCannell denomina «invasión agresiva del área turística por parte de los intereses corporativos de la industria del entretenimiento» empobrece y desvirtúa la llamada autenticidad de la experiencia del viaje.

\subsection{Imágenes y mercancía experiencial}

Uno de los rasgos definitorios del turismo es la apropiación y objetivación de las experiencias de viaje en forma de imágenes. Ese espectáculo del que hablase Guy Debord tiende a ser objeto de apropiación individual. El hecho de que los turistas vayan provistos de cámaras fotográficas fue observado por Susan Sontag como expresión del deseo de certificar el viaje. Pero, al mismo tiempo que la fotografía satisface la necesidad de documentar la experiencia turística, la desnaturaliza en el momento en que la obsesión por encontrar lo fotogénico sustituye a la experiencia vivida: «El viaje se transforma en una estrategia para acumular fotos. La propia actividad fotográfica es tranquilizadora, y mitiga esa desorientación general que se suele agudizar con los viajes» (Sontag, 1996: 24).

Como mercancía experiencial, la visita turística se enmarca en el consumo conspicuo de un estilo de vida (Watson y Kopachesvsky, 1994). En una era en la que, antes que los objetos tangibles, lo que se valora es el acceso (Rifkin, 2000) y el capital inmaterial (Gorz, 2003), el turismo representa un vector de diferenciación social. Forma parte del capitalismo cultural en el que tanto las culturas como formas de vida, como la cultura en tanto acervo patrimonial de obras artísticas, se consumen como experiencias mercantilizadas. 
El turismo representa hoy la manifestación no solo de un poder pecuniario, sino de todo un lifestyle basado en la cultura del entertainment (Rifkin, 2000: 94). Esa mercancía experiencial ha de mostrarse como parte del ocio conspicuo y ostentativo del que nos hablaba Thorstein Veblen (2014). Las imágenes registradas y mostradas representan el certificado de realidad del viaje turístico como parte de la identidad social de los turistas.

Los elementos de distinción social, por utilizar términos de Pierre Bourdieu, no se establecen solamente entre quienes viajan y quienes no. Existe un deber de placer que se refiere en este caso a la experiencia turística como fruición y divertimento (Bourdieu, 2006: 371). Entre los turistas también hay diferencias perceptibles y ostensibles: entre la masa estandarizada y los llamados turismos culturales, de aventura o incluso el dark tourism (Smith, 2002) con visitas a los Lager del Holocausto judío en Auschwitz o los gulags soviéticos.

Hay modos considerados correctos e incorrectos de hacer turismo, que son el reflejo de la pertenencia a grupos sociales determinados. Las prescripciones sobre lo que sea de obligada visita se contraponen así a la lógica errante del merodeo en los viajes: «La vergüenza turística no consiste en ser turista, sino en no serlo lo suficiente, en no observar todo del modo en que "debería" ser observado» (MacCannell, 2003: 15).

El derecho de entrada al llamado mundo culto se vuelve así un factor de enclasamiento. Dentro de lo permitido y lo prohibido en el viaje turístico, las competencias artísticas y las visitas obligadas articulan las formas aceptadas de viajar. Así ocurre con las visitas a los museos: «El turismo reactiva los sentimientos de obligación que son constitutivos del sentimiento de pertenecer al mundo culto» (Bourdieu, 2003: 54). La distinción se hará, pues, entre aquellos que son capaces de descifrar los sentidos de las obras de arte, por un lado, y aquellos otros que simplemente están limitados a aprehender el arte en su puro aspecto fenoménico (Bourdieu, 2003: 87).

\section{EL TURISTA HIPERCONECTADO}

Los medios de comunicación han representado lo que Émile Durkheim llamaba un corps intermédiaire, como la escuela o la familia. Se trata de constructos sociales que intermedian la experiencia (Thompson, 1998) y, de esta manera, influyen tanto en la conformación de las formas de pensamiento como de acción (Giddens, 1995). 
Los medios de comunicación transmiten y conforman una «personalidad de base» (Debray, 2001: 15). No solamente son los medios las instituciones que describen los mundos de vida, sino que también los prescriben en tanto «transmitir es organizar, y organizar es jerarquizar» (Debray, 2001: 25).

La comunicación que se refiere a lo fugaz, a lo instantáneo, se ha convertido hoy en el eje organizador de las prácticas sociales. En cierto modo, la tecnología digital es una suerte de Digital Ground (McCullough, 2005), la base común que sirve de infraestructura para las vidas cotidianas. Y también para los turistas y sus viajes, por ejemplo, a través del GPS (Global Positioning System), los tagged places y los RFID (Radio Frequency Identification) (McCullough, 2005: 81).

El smartphone se ha conformado como una prótesis permanente del ser humano y, por extensión, del turista. Por tanto, es un mediador omnipresente que intensifica el poder tecnológico (Sfez, 2007: 19).

\subsection{Viajar hiperconectado}

Paul Virilio señalaba que, con la generalización de las nuevas tecnologías, bajo la impresión de velocidad y movimiento perpetuo, se escondía un sedentarismo absoluto. Una vez hipermediados por los dispositivos digitales y, en nuestro caso, por el smartphone, la hiperconexión y el always on hace que en los viajes el turista lleve consigo todo su haz de relaciones interpersonales en tiempo real (Virilio, 2007: 99).

$\mathrm{Y}$, al mismo tiempo, supone una nueva mediación de las percepciones, además de un factor de distracción que implica privación sensorial, una vez el usuario se halla en el vehículo audiovisual que es el smartphone (Virilio, 2009: 78).

En efecto, al portar el usuario de redes todo su mundo virtual consigo, el viaje se convierte en algo domesticado y el nómada se transforma en un sedentario absoluto. Allá donde vaya, nos dice Virilio, lleva a cuestas sus familiaridades. Y también todo el conjunto de opiniones y consejos que sirven de guías para los itinerarios, como los alojados en TripAdvisor. Se trata de guías de viaje basadas ahora en user generated media.

El vehículo que es el smartphone se convierte en un remedo de esos otros vehículos que encapsulan y aíslan al individuo de su entorno. Son prótesis que conectan a los mundos virtuales y distantes, al mismo tiempo que desconectan de entornos próximos, una especie de burbujas profilácticas (Dupuy, 2002: 61). 
La actualización permanente a través del smartphone ratifica el sentido de desrealización de los acontecimientos del que nos hablaba Jean Baudrillard. La autenticidad buscada y reclamada por el turista se enfrenta también a su inclusión en el sistema de informaciones transmitidas en tiempo real, «une immense machine à produire l'événement comme signe, comme valeur échangeable sur le marché universel de l'idéologie» (Baudrillard, 2004: 103).3

Por otra parte, la hiperconexión permite al viajero durante el desplazamiento servirse de mapas en tiempo real, de geolocalización, así como de guías sobre el territorio. Se trata entonces de un viaje tutelado en tiempo real, más seguro y, por tanto, con menos lugar a lo inesperado. En una burbuja digital (Pariser, 2011), la sensación de invulnerabilidad viaja con el turista. Es como una suerte de espacio interior de confort: el viaje a bordo de una especie de invernadero, según la metáfora de Peter Sloterdijk (Sloterdijk, 2007).

La necesidad de ruptura del viaje queda así en suspenso una vez el uso del smartphone conecta a los turistas a sus vidas cotidianas. Como resistencia, nacen corrientes de desconexión voluntaria (Jauréguiberry, 2016). A la necesidad de quedarse al margen, propia del viaje, se contrapone la obligación de estar siempre disponible en el smartphone, con síndromes como el miedo a perderse algo o FOMO (Fear of Missing Out). El aventurero Erling Kagge así lo hacía notar: «Poder alejarse del ruido cotidiano es un privilegio» (Kagge, 2017: 85).

\subsection{Las imágenes y los relatos en red}

Además de remitirnos a su aversión hacia los viajes, Lévi-Strauss contaba en las primeras páginas de Tristes Trópicos (1998) que el sacrificio que realizaba al viajar se justificaba solo por los descubrimientos relevantes.

Los relatos de viaje han oscilado históricamente entre la invención y el registro fidedigno de lo acontecido. Al contar el viaje, la búsqueda de lo insólito se conjuga en la modernidad con la intención, no ya de transformar lo visto, sino de reproducirlo (Pimentel, 2003: 63). Es lo reflejado a modo satírico en Los viajes de Gulliver de Jonathan Swift, tal y como lo confiesa en su capítulo XII:

Así, amable lector, te he hecho un fiel retrato de mis viajes durante dieciséis años y más de siete meses, en el que no me he afanado tanto por embellecerlo como por decir la verdad. Hubiera podido, tal vez, al igual que otros, asombrarte con extrañas e inverosímiles

«Una inmensa máquina para producir el acontecimiento como signo, como valor intercambiable en el mercado universal de la ideología» (traducción de los autores). 
historias, mas he preferido relatar llanamente los hechos en la forma y estilo más sencillos, ya que mi primera intención es instruir y no deleitarse (Swift, 1999: 268-269).

El relato del viaje hoy no ha de esperar a la vuelta. El tiempo real del smartphone hace que el turista pueda compartir y certificar sus vivencias en las redes. Tendencias tales como el selfie tourism (Walsh y Baker, 2016; Dinhopl y Gretzel, 2016) y el travelgram dan cuenta de la necesidad de autoexposición. Ya sea como una manifestación del narcisismo contemporáneo (Barry et al., 2017), o como plataforma para mantenerse en comunicación con las redes personales, el selfie dificulta tanto la necesidad de separación respecto a lo familiar en el segundo caso como la apertura al exterior, a la alteridad, en el primero.

El viaje se convierte así en un acto social. El relato en tiempo real responde a la necesidad de hacerse ver (Aubert y Haroche, 2013) en el espacio virtual. Para sentir la propia existencia, las fotografías son un expediente de vida. Transmitidas en tiempo real, en lugar del barthesiano (Barthes, 1980) esto-hasido, lo que se comunica es el estoy-siendo.

En lugar de abrirse al exterior, la atención del turista se dirige a su presencia, de forma que el escenario de destino queda en segundo plano, como un paisaje exótico que sirve de marco excepcional para su propia imagen. En $\mathrm{La}$ société du spectacle, Debord aludía al fenómeno de la vedetización: «Les vedettes existent pour figurer des types variés de styles de vie et de styles de compréhension de la société, libres de s'exercer globalment» (Debord, 2006: $785) \cdot{ }^{4}$

La experiencia del viaje pasa a ser el pretexto para ser fotografiado y compartido. Se eligen los destinos en función de su instagramabilidad, es decir, conforme a los criterios de espectacularidad que hacen de una imagen un objeto de atracción y visibilidad. Si un destino turístico se presta a convertirse en escenario para fotografías y vídeos que alcanzarán un mayor número de visualizaciones, ese destino será instagramable. Lo que pasa a primer plano es el hecho social de compartir y exhibir la propia vida fotografiada, en forma de pose. La experiencia interior parece ser algo tangencial, como bien advertía Kracauer a propósito de la banalización de la fotografía: «El torbellino de nieve de las fotografías revela la indiferencia frente a lo que las cosas se refieren» (Kracauer, 2008: 33).

«Las vedettes existen para representar tipos variados de estilos de vida y de estilos de comprensión de la sociedad, libres de ejercerse globalmente» (traducción de los autores). 


\section{CONCLUSIONES}

Con la democratización de los viajes, el turismo ha permitido abrir horizontes de conocimiento a un mayor número de ciudadanos. No obstante, el aumento cuantitativo suscita dudas en cuanto a la naturaleza cualitativa de esos desplazamientos. El ideal de viaje que hemos delineado nos ayuda a construir los siguientes ejes para la discusión crítica sobre el turismo contemporáneo y su relación con el smartphone.

El hecho de desplazarse en el espacio no significa que el viajero incorpore conocimientos nuevos. La apertura cognitiva al encuentro con el otro antropológico es una condición de esa transformación interior, que reside en la naturaleza de lo que Sterne llamaba «viaje sentimental». La discusión se plantea en torno a una tecnología de hiperconexión, como el smartphone que dificulta la separación respecto a los ámbitos de familiaridad del viajero hiperconectado. La necesidad de alejamiento respecto a la vida cotidiana no es compatible con la generalización del smartphone como prótesis del viajero.

La curiosidad hacia lo desconocido entra en conflicto con un turismo mercantilizado, así como con los algoritmos del smartphone (Carr, 2011: 262), que proporcionan un viaje controlado y previsible. En su relato sobre el Danubio, Claudio Magris sugería: «In ogni viaggio c’è almeno un frammento di Sud, ore distese, abbandono, fluire dell'onda» (Magris, 2015: 16).5 En este sentido, el smartphone puede intensificar la racionalización de los viajes como itinerarios donde cada turista debe ver lo ya estipulado.

La sorpresa y lo inesperado forman parte de la experiencia natural del viaje. Aplicaciones tanto para preparar el viaje, como durante el viaje mismo, despojan al desplazamiento de su dimensión aleatoria. En sus Paseos por Roma, Stendhal nos decía: «Acabamos por errar casi a la aventura. Hemos saboreado la felicidad de estar en Roma con toda libertad y sin pensar en el deber de ver» (Stendhal, 2015: 47).

El smartphone permite hoy relatar el viaje en tiempo real. La toma de fotografías, así como el hecho de compartirlas en red, conlleva una doble consecuencia. Por una parte, sirve de certificado de presencia que distingue y enclasa a los turistas, que construyen su imagen virtual mediante estas series de instantáneas, muestras de un lifestyle. Por otra parte, mientras el turista se rige por los criterios de instagramabilidad, la autenticidad de la experiencia sufre

«En cada viaje hay al menos un fragmento de sur, de horas distendidas, de abandono, de fluir en la onda» (traducción de los autores). 
otra merma en su naturaleza aurática. De los paisajes humanos y geográficos convertidos en atracción turística, en imagen, pasamos a las imágenes tomadas por el turismo y compartidas en tiempo real. La relación de imágenes con imágenes que describiera Debord se intensifica.

El modelo normativo al que se contraponen estas prácticas del viaje, enraizadas en la experiencia mercantilizada del turismo, podría definirse como un cruce entre el reconocimiento y la resonancia. Son dos conceptos prácticos, delineados desde la sociología alemana por Axel Honneth (2007) y por Hartmut Rosa (2019), encaminados a combatir tanto la reificación que devalúa la experiencia del viaje como la aceleración creciente de las prácticas turísticas, convertidas en bien de consumo. La teoría crítica del turismo se dirige así a la recuperación de la experiencia sensorial del viaje como reconocimiento de la alteridad, en lucha contra el hecho de «vivenciar las propias sensaciones y los propios deseos como entidades cósicas» (Honneth, 2007: 125). El viaje transformado en turismo, en experiencia cosificada y mercantilizada, sirve como factor de alienación de una de las prácticas fundamentales de una suerte de nomadismo mental, a través del movimiento en el espacio.

La crítica al turismo también debe dar cuenta del restablecimiento de una sensorialidad plena en el contexto de experiencias alienadas: «Este mundo que se ha convertido en algo disponible parece volverse mudo, gris y vacío delante nuestro, nos deja fríos. Los lugares a los que viajamos no nos emocionan, las personas con las que nos encontramos nos dejan indiferentes» (Rosa, 2019: 59).

Con todo, la experiencia del turista, ya tienda a la estandarización y la superficialidad o a la ampliación de saberes sobre la alteridad, depende de la voluntad, o no, de sortear esos obstáculos que vuelven rígidos los viajes. En medio de itinerarios prefijados y paisajes estereotipados, el viajero puede, como diría de Certeau, vivenciar los desplazamientos mediante otras tácticas no prescritas. Ocurrió así en la gran excursión a Europa y Tierra Santa que realizó Mark Twain, cuyas impresiones fueron consignadas, con su habitual ironía, en Guía para viajeros inocentes:

Viajar es nefasto para el prejuicio, la intolerancia y la estrechez de miras; y muchos de los nuestros lo necesitan desesperadamente por este motivo. Un punto de vista caritativo, abierto y sano de los hombres y las cosas no se consigue vegetando toda nuestra vida en el mismo rincón de la tierra (Twain, 2016: 621). 


\section{BIBLIOGRAFÍA}

Adorno, Theodor y Horkheimer, Max (2004). Dialéctica de la ilustración. Madrid: Trotta (6. - edición).

Alaluf, Yaara Benger (2019). «Todo incluido, menos el estrés»: la producción de relax en sedes del Club Med junto al mar. En Illouz, Eva (comp.). Capitalismo, consumo y autenticidad: las emociones como mercancía. Madrid: Katz.

Aubert, Nicole y Haroche, Claudine (Eds.) (2013). Farsi vedere: la tirannia della visibilitá nella societá di oggi. Milano: Giunti.

Augé, Marc (1998). El viaje imposible. Barcelona: Gedisa.

Augé, Marc (2007). Antropología de la movilidad. Barcelona: Gedisa.

Bachelard, Gaston (1993). Poética del espacio. Madrid: FCE.

Barry, Christopher T., Doucette, Hanna, Loflin, Della C., RiveraHudson, Nicole y Herrington, Lacey L. (2017). "Let me take a selfie": Associations between self-photography, narcissism, and self-esteem. Psychology of Popular Media Culture, 6(1), 48-60. https://doi.org/10.1037/ppmooooo89

Barthes, Roland (1980). La chambre claire. Paris: Gallimard.

Baudelaire, Charles (2007). Les fleurs du Mal (édition de 1861). Paris: Chêne.

Baudelaire, Charles (2008). Spleen de Paris. Pequeños poemas en prosa. Madrid: Visor Libros.

Baudrillard, Jean (2004). Le pacte de lucidité ou l'intelligence du Mal. Paris: Galilée.

Belmonte, María (2015). Peregrinos de la belleza. Barcelona: El Acantilado.

Boorstin, Daniel (200o). Los descubridores. Barcelona: Crítica.

Bourdieu, Pierre (2003). El amor al arte: los museos europeos y su público. Barcelona: Paidós Ibérica.

Bourdieu, Pierre (2006). La distinción: criterios y bases sociales del gusto. Madrid: Taurus.

Brunel, Sylvie (2006). La planète disneylandisée. Paris: Science Humains Éditions. 
Carr, Nicholas (2011). Superficiales. Madrid: Taurus.

Cohen, Erik (2005). Principales tendencias en el turismo contemporáneo. Política y Sociedad, $42(1), 11-24$.

Cohen, Erik y Spector, Sam (Eds.) (2019). Space Tourism: the Elusive Dream. Bingley: Emerald Publishing.

Debord, Guy (2006). Euvres. Paris: Gallimard.

Debray, Regis (2001). Introducción a la mediología. Barcelona: Paidós.

Dickens, Charles (2010). El viajero sin propósito. Madrid: Gadir.

Dickinson, Janet E., Ghali, Karen, Cherrett, Tom, Speed, Chris, Davies, Nigel y Norgate, Sarah (2014). Tourism and the smartphone app: capabilities, emerging practice and scope in the travel domain. Current Issues in Tourism. 17(1), 84-101.

Dinhopl, Anja y Gretzer, Ulrike (2016). Selfie-taking as touristic looking. Annals of Tourism Research, 57, 126-139.

Dupuy, Jean-Pierre (2002). Pour une catastrophisme éclairé. Paris: Éditions du Séuil.

Encinas Reguero, M. Carmen. (2018). El viaje en la tragedia griega. Cuadernos de Filología Clásica. Estudios griegos e indoeuropeos, 28, 101113.

Feifer, Maxine (1985). Going Places: the ways of the tourist from Imperial Rome to the present day. London: MacMillan.

Giddens, Anthony (1995). Modernidad e identidad del yo. Barcelona: Península.

Gorz, André (2003). L'immatériel: connaissance, valeur et capital. Paris: Galilée.

Honneth, Axel (2007). Reificación. Barcelona: Katz.

Honneht, Axel (2009). Crítica del poder. Madrid: Antonio Machado. Jauréguiberry, Francis (2016). Le voyageur hypermoderne: partir dans un monde connecté. Toulouse: Érès.

Kagge, Erling (2017). El silencio en la era del ruido. Barcelona: Taurus. Kracauer, Siegfried (2008). La fotografía y otros ensayos. Barcelona: Gedisa.

La Cecla, Franco (2011). Perdersi: l'uomo senza ambiente. Roma: Laterza. 
Le Breton, David (2019). Desaparecer de sí. Madrid: Siruela.

Lecoquierre, Bruno (2008). Parcourir la terre: le voyage, de l'exploration au tourisme. Paris: L'harmattan.

Lefebvre, Henri (1981). Critique de la vie quotidienne III. Paris: L'arche éditeur.

Lévi-Strauss, Claude (1998). Tristes trópicos. Barcelona: Paidós Ibérica.

MacCannell, Dean (2003). El turista: una nueva teoría de la clase ociosa. Barcelona: Melusina.

Magherini, Graziella (1996). Lo sindrome Stendhal. Milano: Ponte alle Grazie.

Magris, Claudio (2015). Danubio. Milano: Garzanti.

Manguel, Alberto (2015). Historia natural de la curiosidad. Madrid: Alianza.

McCullough, Malcolm (2005). Digital Ground. Cambridge: MIT Press.

Melville, Herman (2009). Moby Dick. Madrid: Alianza.

Ossola, Carlo (2012). Curiositas y Nonchalance: de la proximidad a la distancia. En Jarauta, Francisco (Ed.). Historia y formas de la curiosidad. Santander: Fundación Botín.

Pariser, Eli (2011). The Filter Bubble. London: Viking.

Perniola, Mario (2008). Los situacionistas. Madrid: Acuarela \& A. Machado libros.

Pimentel, Juan (2003). Testigos del mundo: ciencia, literatura y viajes en la Ilustración. Madrid: Marcial Pons.

Rifkin, Jeremy (200o). La era del acceso. Barcelona: Paidós Ibérica.

Ritzer, George (200o). El encanto de un mundo desencantado. Barcelona: Ariel.

Ritzer, George (2002). La McDonalización de la sociedad. Barcelona: Ariel.

Rosa, Hartmut (2019). Remedio a la aceleración: ensayos sobre la resonancia. Barcelona: NED.

Sfez, Lucien (2007). La communication. Paris: PUF. 
Shklovski, Viktor (2012). El arte como artificio. En Todorov, Tzvetzn (Ed.) (2012). Teoría de la literatura de los formalistas rusos. Madrid: Biblioteca Nueva.

Simmel, Georg (1986). La metrópolis y la vida mental. En Simmel, Georg. El individuo y la libertad. Barcelona: Península.

Sloterdijk, Peter (2007). En el mundo interior del capital. Madrid: Siruela. Smith, Wayne M. (2002). Dark Tourism: the Attraction of Death and Disaster. Annals of Tourism Research, 29(4): 1188-1189.

Sontag, Susan (2006). Sobre la fotografía. México: Santillana.

Soriano, Nieves (2009). Viajeros románticos a Oriente. Murcia: Editum.

Stendhal (2015). Paseos por Roma. Madrid: Alianza (2. edición).

Sterne, Laurence (2017). Viaje sentimental. Barcelona: Penguin.

Stevenson, Robert Louis (2014). Viajar: ensayos sobre viajes. Madrid:

Páginas de espuma.

Swift, Jonathan (1999). Los viajes de Gulliver. Madrid: Alianza.

Tabucchi, Antonio (2012). Viajes y otros viajes. Barcelona: Anagrama.

Thompson, John B. (1998). Los media y la modernidad. Barcelona: Paidós.

Twain, Mark (2016). Guía para viajeros inocentes. A Coruña: Ediciones del Viento (6..$^{\text {a }}$ edición).

Urry, John (1990). The Tourist Gaze: Leisure and Travel in Contemporary Societies. London: Sage.

Urry, John y Larsen, Jonas (2011). The Tourist Gaze 3.o. London: Sage.

Veblen, Thorstein (2014). Teoría de la clase ociosa. Madrid: Alianza.

Virilio, Paul (2007). L'université du désastre. Paris: Galilée.

Virilio, Paul (2009). Le futurisme de l'instant. Paris: Galilée.

Walsh, Michael James y Baker, Stephanie Alice (2016). The selfie and the transformation of the public-private distinction. Information, Communication \& Society, 20(8), 1185-1203. https://doi.org/10.1080/1369118X.2016.1220969

Wang, Ning (2000). Tourism and Modernity: A Sociological Analysis. Bingley: Pergamon. 
Watson, G. Llewellyn y Kopachevsky, Joseph P. (1994). Interpretations of Tourism as Commodity. Annals of Tourism Research, 21(3), 643660.

Weber, Max (1993). Economía y sociedad. Madrid: FCE.

Woolf, Virginia (2001). Viajes y viajeros. Barcelona: Plaza \& Janes.

Wulf, Cristoph (2008). Antropología: historia, cultura, filosofía. Barcelona: Anthropos.

Xue, Lan, Manuel-Navarrete, David y Buzinde, Christine (2014). Theorizing the concept of alienation in tourism studies. Annals of Tourism Research, 44(1), 186-199. https://doi.org/10.1016/j.annals.2013.10.001

Zumthor, Paul (1994). La medida del mundo. Madrid: Cátedra.

Zweig, Stefan (2016). Viajar o «ser viajado». En De viaje. La India y América. Madrid: Sequitur. 